\title{
Muscle Fatigue Analysis of Hilly Women of Meghalaya Involved in Sericulture Activities
}

\author{
Swapnali Borah* and Nilakshi Borah \\ College of Community Science, Central Agricultural University, Tura, Meghalaya, India \\ *Corresponding author
}

\begin{abstract}
A B S T R A C T
Keywords

Rodgers Muscle Fatigue Analysis, Meghalaya,

Sericulture

Activities, Work

Related

Musculoskeletal Disorder, East Garo Hills

\section{Article Info}

Accepted:

15 December 2020

Available Online:

10 January 2021

Work risk is an inescapable part of hilly tribal women of Meghalaya involved in Sericulture industry. Women workers mainly of reproductive age groups were affected by work risk. The aim of this research was to analysis muscle fatigue of hilly women in sericulture industry so that work related musculoskeletal disorders (WMSDs) can be prevented. Thirty women workers from East Garo Hills of Meghalaya were selected randomly for the purpose of the study and the activity of sericulture was divided into three parts viz. rearing of worm, extracting of pupa from cocoon and reeling of fibre for in depth study of the activity. Rodgers muscle fatigue analysis tool was used to assess the amount of fatigue that accumulates in muscles during various works and to know risk level for each body regions. Result showed that upper limbs, neck and back were affecting in all activities of sericulture industry and particularly exertion risk was high in wrist, arm and hand while extracting pupa from cocoon.
\end{abstract}

\section{Introduction}

The silk industry plays an important part in Textile Industry and Export and has a particular position in India. As manufacturer of silk in the region of the world where India got the $2^{\text {nd }}$ largest position with $19690 \mathrm{MT}$ and also the largest user of silk in the world (Syed Yaseen 2013). Mulberry, Eri, Tussar and Muga are the four known varieties of silk which are produced in India (Savithri, et al., 2013) where Mulberry is largest practiced in the country and Mulberry silk production gives almost $80 \%$ for entire silk production. Meghalaya is one of the eight states of NorthEast India where sericulture is a major cottage based eco friendly industry in rural areas of East Garo Hills. Rural hilly tribal women are the most dominant part of these industries and they are doing almost all the activities of sericulture from rearing of worms to reeling.

In sericulture industry, lots of physical as well as occupational health hazards faced by women involved in all the activities from rearing of worms (i.e. onward journey to the 
forest, collection of leaves in the forest, backward journey from the forest), extraction of pupa from cocoon to reeling of silk fibre as all are more laborious and tedious. Farm women had musculoskeletal discomforts due to repetitive nature of job, use of some conventional tools and carrying heavy load while collecting castor and kesseru leaves from undulating areas of hilly forest.

Most of the rural farm workers mainly reproductive age groups were also affected by work related risk as work risk is an unavoidable part of hilly tribal women of Meghalaya who involved in sericulture industry. Work risk was high while they were doing extraction of pupa from cocoon by threshing of cocoon in their fingers in a repetitive manner in which fingers, wrist and hands were affecting due to monotonous work. Therefore, this study was carried out to obtain knowledge on drudgery of hilly women involved in sericulture industries of Meghalaya by using Muscle Fatigue Analysis

\section{Materials and Methods}

Thirty rural farm women with age group 2050 years engaged in Sericulture industry were selected by purposive sampling method from two villages of Samanda Block of East Garo Hills district of Meghalaya. One interview schedule was structured having three parts viz. rearing of worms, collection of cocoons and reeling.

Again rearing section were sub divided into onward journey to the forest, collection of leaves in the forest and backward journey from the forest. We had adopted muscle fatigue analysis which was proposed by Rodger (Rodgers S.H., 1992) as a means to assess the amount of fatigue that accumulate in muscle during various work pattern within 5 minutes of work.

\section{Rodgers muscle fatigue analysis}

The amount of fatigue that increases in muscles through various work patterns within 5 minutes of work can be measured by Rodgers Muscle Fatigue Analysis. The hypothesis of this method undergoes a rapidly tiring muscle is more at risk to injury and inflammation. Muscle Fatigue Analysis was suitable to assess the risk for tiredness assembling in tasks that are carried out for an hour or extra hour and where frequent exertions or awkward postures are present. A Priority for Change can be allotted to the task depends on the risk of fatigue.

To assess the muscle fatigue analysis by task of farm women involved in sericulture activities used a separate task questionnaire. In this task questionnaire assessment was done on the basis of the risk of fatigue for each of the seven body regions i.e. neck, shoulders, back, arms/elbows, wrists/hands/fingers, legs/knees and ankles/feet/toes. A priority for change was assigned to the task in the order of effort type, duration of effort and frequency of effort. Once an Effort Level is selected to perform a task within the body, the task of Continuous Effort Time and Effort per minutes must be associated with chosen effort. Most of the worker could not completed the task if the effort level is high enough but the Continuous Effort Duration is more than $30 \mathrm{sec}$ or frequency is more than $15 / \mathrm{min}$ then the task is a very high priority for change.

\section{Results and Discussion}

\section{Muscle Fatigue Analysis of farmwomen while doing onward journey to forest}

The results of Muscle fatigue analysis was done for women engaged in rearing of worms in sericulture and presented in Table1. The data reveals that legs/knees and 
ankle/feet/toes were the body regions had moderate priority at the time of onward journey to the forest. While doing this activity farm women had to travel from their farm to the hilly forest in search of castor and kesseru leaves and therefore legs, knees were affecting. Results revealed that low priority was observed in some body regions like neck, shoulders, back etc.

\section{Muscle Fatigue Analysis of farmwomen while collecting leaves in the Forest}

Muscle Fatigue Analysis while collecting castor and kesseru leaves in the forest for rearing silkworm is presented in Table 2 . It is found from the table that high priority was seen in neck, shoulders, back, arm/elbow and fingers/wrist/hands as these body parts were affected most. In search of leaves farm women had to travel here and there in the forest to collect Castor and Kesseru leaves and carried on their back with a heavy load of fresh leaves in their kokcheng (a native bamboo basket). Collection of leaves is being tedious as they had to travel long way to collect fodder for silkworm and while collecting leaves they had to adopt static and dynamic unnatural body posture like stooping, stretching, twisting their body etc. Borah (2015) opined that Garo women collected firewood from faraway places of hilly forest of West Garo Hills with simple dao where they had to suffer lots of difficulties particularly severe pain in lower and upper back, neck, hand and wrist along with insect and snake bite. At the end of the workday constant standing in the workplace can cause pain and fatigue in muscles particularly in the lower extremities of workers. Further analysis of the data on collection of leaves in the forest medium priority was found in legs/knees and ankles/feet/toes.

Table.1 Muscle Fatigue Analysis for onward journey of women from the forest $(\mathrm{N}=30)$

\begin{tabular}{|c|c|c|c|c|}
\hline \multirow[t]{2}{*}{ Body Parts } & \multicolumn{3}{|c|}{ Scores } & \multirow[t]{2}{*}{ Priority } \\
\hline & Effort & Duration & Frequency & \\
\hline Neck & 1.2 & 1.9 & 1.8 & $\mathrm{~L}$ \\
\hline \multirow[t]{2}{*}{ Shoulders } & Right 1.3 & 1.8 & 1.8 & $\mathrm{~L}$ \\
\hline & Left 1.2 & 1.7 & 1.7 & $\mathrm{~L}$ \\
\hline Back & 1.4 & 1.7 & 1.8 & $\mathrm{~L}$ \\
\hline \multirow[t]{2}{*}{ Arms/Elbow } & Right 1.4 & 1.8 & 1.7 & $\mathrm{~L}$ \\
\hline & Left $\quad 1.2$ & 1.3 & 1.3 & $\mathrm{~L}$ \\
\hline \multirow[t]{2}{*}{ Wrists/Hands/Fingers } & Right 1.3 & 1.6 & 1.2 & $\mathrm{~L}$ \\
\hline & Left $\quad 1.2$ & 1.5 & 1.3 & $\mathrm{~L}$ \\
\hline \multirow[t]{2}{*}{ Legs/Knees } & Right 1.2 & 1.7 & 2.7 & M \\
\hline & Left $\quad 1.4$ & 1.8 & 2.9 & M \\
\hline \multirow[t]{2}{*}{ Ankles/Feet/Toes } & Right 1.6 & 1.8 & 1.7 & M \\
\hline & Left $\quad 1.7$ & 1.9 & 1.8 & M \\
\hline $\begin{array}{c}\text { Continuous Effort } \\
\text { Duration }\end{array}$ & $\begin{array}{c}<6 \mathrm{~s} \\
1\end{array}$ & $\begin{array}{c}6-20 s \\
2\end{array}$ & $\begin{array}{c}20-30 \mathrm{~s} \\
3\end{array}$ & $\begin{array}{c}>30 \mathrm{~s} \\
4 \text { (Enter VH for Priority) }\end{array}$ \\
\hline Effort Frequency & $<1 / \min$ & $\begin{array}{c}1-5 / \mathrm{min} \\
2\end{array}$ & $\begin{array}{c}>5-15 / \mathrm{min} \\
3\end{array}$ & $\begin{array}{l}>15 / \text { min } \\
\text { 4(Enter VH for Priority) }\end{array}$ \\
\hline
\end{tabular}


Table.2 Muscle Fatigue Analysis for women engaged in collection of leaves in the forest $(\mathrm{N}=30)$

\begin{tabular}{|c|c|c|c|c|}
\hline \multirow[t]{2}{*}{ Body Parts } & \multicolumn{3}{|c|}{ Scores } & \multirow[t]{2}{*}{ Priority } \\
\hline & Effort & Duration & Frequency & \\
\hline Neck & 2.9 & 2.4 & 2.3 & $\mathrm{H}$ \\
\hline \multirow{2}{*}{ Shoulders } & Right 2.8 & 1.4 & 3.00 & $\mathrm{H}$ \\
\hline & Left & 1.4 & 3.00 & $\mathrm{H}$ \\
\hline Back & 3.00 & 1.4 & 3.00 & $\mathrm{H}$ \\
\hline \multirow[t]{2}{*}{ Arms/Elbow } & Right 2.8 & 2.2 & 2.3 & $\mathrm{H}$ \\
\hline & Left & 1.5 & 3.00 & $\mathrm{H}$ \\
\hline \multirow[t]{2}{*}{ Wrists/Hands/Fingers } & Right & 2.4 & 2.4 & $\mathrm{H}$ \\
\hline & Left & 2.4 & 2.4 & $\mathrm{H}$ \\
\hline \multirow[t]{2}{*}{ Legs/Knees } & Right & 2.00 & 3.00 & $\mathrm{M}$ \\
\hline & Left & 2.00 & 3.00 & $\mathrm{M}$ \\
\hline \multirow[t]{2}{*}{ Ankles/Feet/Toes } & Right & 2 & 3.00 & $\mathrm{M}$ \\
\hline & Left & 2.2 & 3.00 & M \\
\hline $\begin{array}{c}\text { Continuous Effort } \\
\text { Duration }\end{array}$ & $\begin{array}{c}<6 s \\
1\end{array}$ & $\begin{array}{c}6-20 s \\
2\end{array}$ & $\begin{array}{l}20-30 \mathrm{~s} \\
3\end{array}$ & $\begin{array}{c}>30 \mathrm{~s} \\
4(\text { Enter VH for Priority })\end{array}$ \\
\hline Effort Frequency & $\begin{array}{c}<1 / \min \\
1\end{array}$ & $\begin{array}{c}1-5 / \min \\
2\end{array}$ & $\begin{array}{c}>5-15 / \mathrm{min} \\
3\end{array}$ & $\begin{array}{l}\quad>15 / \mathrm{min} \\
4 \text { (Enter VH for Priority) }\end{array}$ \\
\hline
\end{tabular}

Table.3 Muscle Fatigue Analysis for backward journey of women from the forest (N=30)

\begin{tabular}{|c|c|c|c|c|}
\hline \multirow{2}{*}{ Body Parts } & \multicolumn{3}{|c|}{ Scores } & \multirow{2}{*}{ Priority } \\
\hline & Effort & Duration & Frequency & \\
\hline Neck & 3.4 & 3.2 & 4 & $\mathrm{VH}$ \\
\hline \multirow[b]{2}{*}{ Shoulders } & Right 2.7 & 2.8 & 4 & $\mathrm{VH}$ \\
\hline & Left & 3.00 & 4 & $\mathrm{VH}$ \\
\hline Back & 3.00 & 2.9 & 4 & $\mathrm{VH}$ \\
\hline \multirow[b]{2}{*}{ Arms/Elbow } & Right 2.4 & 1.9 & 3.00 & $\mathrm{M}$ \\
\hline & Left & 1.9 & 4 & $\mathrm{M}$ \\
\hline \multirow[b]{2}{*}{ Wrists/Hands/Fingers } & Right & 2 & 3.1 & M \\
\hline & Left & 2.3 & 3.1 & M \\
\hline \multirow[b]{2}{*}{ Legs/Knees } & Right & 2.4 & 3.4 & $\mathrm{VH}$ \\
\hline & Left & 2.4 & 3.4 & VH \\
\hline \multirow[b]{2}{*}{ Ankles/Feet/Toes } & Right & 2.4 & 3.00 & M \\
\hline & Left & 2.4 & 3.00 & M \\
\hline $\begin{array}{c}\text { Continuous Effort } \\
\text { Duration }\end{array}$ & $\begin{array}{c}<6 \mathrm{~s} \\
1\end{array}$ & $\begin{array}{c}6-20 s \\
2\end{array}$ & $\begin{array}{c}20-30 \mathrm{~s} \\
3\end{array}$ & $\begin{array}{c}>30 \mathrm{~s} \\
\text { 4(Enter VH for } \\
\text { Priority) }\end{array}$ \\
\hline Effort Frequency & $\begin{array}{c}<1 / \min \\
1\end{array}$ & $\begin{array}{c}1-5 / \mathrm{min} \\
2\end{array}$ & $\begin{array}{c}>5-15 / \mathrm{min} . \\
3\end{array}$ & $\begin{array}{l}>15 / \mathrm{min} \\
4(\text { Enter VH for } \\
\text { Priority }\end{array}$ \\
\hline
\end{tabular}


Table.4 Muscle Fatigue Analysis for women engaged in extraction of pupa from cocoon $(\mathrm{N}=30)$

\begin{tabular}{|c|c|c|c|c|}
\hline \multirow[t]{2}{*}{ Body Parts } & \multicolumn{3}{|c|}{ Scores } & \multirow[t]{2}{*}{ Priority } \\
\hline & Effort & Duration & Frequency & \\
\hline Neck & 2.00 & 1.83 & 3.00 & $\mathrm{H}$ \\
\hline \multirow[t]{2}{*}{ Shoulders } & Right 2.3 & 1.80 & 3.00 & $\mathrm{H}$ \\
\hline & Left 2.26 & 1.80 & 2.90 & $\mathrm{H}$ \\
\hline Back & 2.00 & 1.87 & 3.00 & $\mathrm{H}$ \\
\hline \multirow[t]{2}{*}{ Arms/Elbow } & Right 2.13 & 1.83 & 2.93 & $\mathrm{H}$ \\
\hline & Left $\quad 2.0$ & 1.97 & 3.00 & $\mathrm{H}$ \\
\hline \multirow[t]{2}{*}{ Wrists/Hands/Fingers } & Right 2.4 & 1.83 & 2.93 & $\mathrm{H}$ \\
\hline & Left $\quad 2.33$ & 1.97 & 3.00 & $\mathrm{H}$ \\
\hline \multirow[t]{2}{*}{ Legs/Knees } & Right 1.46 & 1.43 & 2.10 & $\mathrm{~L}$ \\
\hline & Left $\quad 1.5$ & 1.50 & 2.07 & $\mathrm{~L}$ \\
\hline \multirow[t]{2}{*}{ Ankles/Feet/Toes } & Right 1.47 & 1.37 & 1.97 & $\mathrm{~L}$ \\
\hline & Left $\quad 1.37$ & 1.30 & 1.80 & $\mathrm{~L}$ \\
\hline $\begin{array}{c}\text { Continuous Effort } \\
\text { Duration }\end{array}$ & $\begin{array}{c}<6 s \\
1\end{array}$ & $\begin{array}{c}6-20 s \\
2\end{array}$ & $\begin{array}{c}20-30 \mathrm{~s} \\
3\end{array}$ & $\begin{array}{c}>30 \mathrm{~s} \\
4(\text { Enter VH for Priority })\end{array}$ \\
\hline Effort Frequency & $<1 / \min$ & $1-5 / \mathrm{min}$ & $\begin{array}{r}>5-15 / \mathrm{min} \\
3\end{array}$ & $\begin{array}{c}>15 / \mathrm{min} \\
4(\text { Enter VH for Priority }\end{array}$ \\
\hline
\end{tabular}

Table.5 Muscle Fatigue Analysis for women engaged in reeling of silk fibre (N=30)

\begin{tabular}{|c|c|c|c|c|}
\hline \multirow[t]{2}{*}{ Body Parts } & \multicolumn{3}{|c|}{ Scores } & \multirow[t]{2}{*}{ Priority } \\
\hline & Effort & Duration & Frequency & \\
\hline Neck & 2.00 & 1.83 & 3.00 & $\mathrm{H}$ \\
\hline \multirow[t]{2}{*}{ Shoulders } & Right 2.3 & 1.80 & 3.00 & $\mathrm{H}$ \\
\hline & Left 2.26 & 1.80 & 2.90 & $\mathrm{H}$ \\
\hline Back & 2.00 & 1.87 & 3.00 & $\mathrm{H}$ \\
\hline \multirow[t]{2}{*}{ Arms/Elbow } & Right 2.13 & 1.83 & 2.93 & $\mathrm{H}$ \\
\hline & Left $\quad 2.0$ & 1.97 & 3.00 & $\mathrm{H}$ \\
\hline \multirow[t]{2}{*}{ Wrists/Hands/Fingers } & Right 2.4 & 1.83 & 2.93 & $\mathrm{H}$ \\
\hline & Left $\quad 2.33$ & 1.97 & 3.00 & $\mathrm{H}$ \\
\hline \multirow[t]{2}{*}{ Legs/Knees } & Right 1.46 & 1.43 & 2.10 & $\mathrm{~L}$ \\
\hline & Left $\quad 1.5$ & 1.50 & 2.07 & $\mathrm{~L}$ \\
\hline \multirow[t]{2}{*}{ Ankles/Feet/Toes } & Right $\quad 1.47$ & 1.37 & 1.97 & $\mathrm{~L}$ \\
\hline & Left $\quad 1.37$ & 1.30 & 1.80 & $\mathrm{~L}$ \\
\hline $\begin{array}{c}\text { Continuous Effort } \\
\text { Duration }\end{array}$ & $\begin{array}{c}<6 \mathrm{~s} \\
1\end{array}$ & $\begin{array}{c}6-20 \mathrm{~s} \\
2\end{array}$ & $\begin{array}{c}20-30 s \\
3\end{array}$ & $\begin{array}{c}>30 \mathrm{~s} \\
\text { 4(Enter VH for Priority) }\end{array}$ \\
\hline Effort Frequency & $\begin{array}{c}<1 / \min \\
1\end{array}$ & $\begin{array}{c}1-5 / \mathrm{min} \\
2\end{array}$ & $\begin{array}{c}>5-15 / \mathrm{min} \\
3\end{array}$ & $\begin{array}{c}>15 / \mathrm{min} \\
4(\text { Enter } \mathrm{VH} \text { for Priority })\end{array}$ \\
\hline
\end{tabular}


Muscle Fatigue Analysis of farmwomen while doing backward journey from forest

The result of backward journey from forest showed that the very high priority was in neck, shoulder, back and legs/knees because farm women were carrying a heavy load of fresh castor/kesseru leaves up to $25-30 \mathrm{kgs}$ on their back in kokcheng (a kind of traditional bamboo basket) from forest to feed the silkworms. Another study done by Borah (2015) found that Garo rural tribal women had carried heavy load of firewood up to 40 kgs on their back in kokcheng from forest and perceived by them as heavy to very heavy. Medium priority was observed in arms/elbow, wrists/fingers and feet/toes respectively (Table 3).

\section{Muscle Fatigue Analysis of women while extracting pupa from cocoon}

While doing extraction of pupa from cocoon, farm women threshed the cocoon on their fingers for extracting pupa which was inside the cocoon. As the activity was wearisome and repetitive in nature by threshing of cocoon in fingers in a repetitive manner in which fingers, wrist and hands were affecting due to repetitive job strain. From the data presented in Table 4, it was observed that neck, shoulders, back, arm/elbow and fingers/wrist/hands were affected most and had high priority followed by legs/knees had medium priority and Ankles/Feet/Toes had low priority. Monotonous and tedious tasks with even lightweights result in accumulated local muscle fatigue which is a severe problem in the workplace, and can cause muscle injuries (Shin HJ, Kim JY 2007). Again Borah et al., (2019) studied Rapid Upper Limb Assessment of women workers engaged in cashew nut processing factories of Meghalaya and Assam where women worker had to work for prolong time by adopting squatting posture or sitting on fourfold gunny bag resulted as musculoskeletal disorders and immediate changes was suggested by the study.

\section{Muscle Fatigue Analysis of farmwomen involved in Reeling}

Farmwomen were engaged in reeling fibres from degummed cocoon by using reeling machine while sitting on stool and at a stretch they used to work for 3-4 hours continuously. As the activity was doing for long period of time in which neck, shoulders, hands etc were affecting.

From the table 5 it was observed that high priority was seen in neck, shoulder, back, arm/elbow and wrists/hands/fingers. Low priority was seen in legs/knees, and ankles/feet/toes as they are using a stool or chair for sitting while doing the reeling activity.

In conclusion the sericulture is the important cottage based eco-friendly industry in the rural area of East Garo Hills of Meghalaya where women were engaged actively in this industry. Farmwomen were doing almost all activities of sericulture though most of the activities were laborious and tedious. Majority of these farmwomen were belonging to reproductive age group and it is a great concern that they were affected by work related musculoskeletal disorders.

Therefore ergonomic intervention with awareness of importance of right body posture and improved women friendly tools particularly for pupa extraction activity is highly required to improve their occupational health and provide safety in the workplace. Improved kokcheng which was designed particularly for Garo women of Meghalaya can also be suggested to reduce their drudgery while collecting fodder leaves from hilly forest (Borah, 2016). 


\section{Acknowledgement}

This is a part of the project of AICRP-Home Science (FRM component), funded by CIWA, ICAR, Bhubaneswar.

\section{References}

Borah S, Chetia D, Marak T.R, Chauhan N. S, and Kumar A (2019) Musculoskeletal Disorder Faced by Women Workers in Cashew Nut Processing Industries of North-East India. Anthropologist, 38(13): 1-8.

Borah, S. (2015) Physiological workload of hill farm women of Meghalaya, India involved in firewood collection. Procedia Manufacturing, 3: 4984-4990.

Borah, S. (2016) Improved kokcheng (improved basket) - for hilly tribal women of Meghalaya. CAU News letter. Vol. 7(2):5.

Rodgers, S. H (1992) A functional job evaluation technique, in Ergonomics, edited by J.S. Moore and A. Garg, Occupational Medicine: State of the Art Reviews. Vol 7(4):679-711.

Savithri G., Sujathamma P. and Neeraja P. (2013) Indian sericulture industry for sustainable rural economy. Int.journal of Economics, commerce and research. Vol 3(2):73-78.

Shin HJ, Kim JY (2007) Measurement of trunk muscle fatigue during dynamic lifting and lowering as recovery time changes. International Journal of Industrial Ergonomics 37:545-551.

Syed Yaseen (2013) "Indian Sericulture Industry: Its Importance, Problems and Prospects", Acme Intellects Journal of Research in Management. Vol 2 (2).

\section{How to cite this article:}

Swapnali Borah and Nilakshi Borah. 2021. Muscle Fatigue Analysis of Hilly Women of Meghalaya Involved in Sericulture Activities. Int.J.Curr.Microbiol.App.Sci. 10(01): 22762282. doi: https://doi.org/10.20546/ijcmas.2021.1001.263 